\title{
Residential Care Directors' Perceptions of Desirable Characteristics of Caregivers for Orphaned and Separated Children
}

\author{
Blen M. Biru ${ }^{1}$ (D) $\cdot$ Rae Jean Proeschold-Bell ${ }^{1,2}$ (D) Bonnie N. Kaiser ${ }^{3,4}$ (D) \\ Heather E. Parnell ${ }^{1,2}$ • Venkata Gopala Krishna Kaza ${ }^{5}$. Ira Madan ${ }^{5}$. \\ Misganaw Eticha Dubie ${ }^{6}$. Vanroth Vann ${ }^{7}$. Cyrilla Amanya ${ }^{8}$. \\ Kathryn Whetten ${ }^{1,2,9}$
}

Accepted: 3 August 2020 / Published online: 14 August 2020

(C) Springer Nature Switzerland AG 2020

\begin{abstract}
Caring for, raising, and educating orphaned and separated children (OSC) is important work that is critical to the long-term well-being of those children. Despite the importance of caregiving, it can be overwhelming and stressful. Much of the available literature addresses the burdens of caregiving, without addressing the positive characteristics that caregivers need to deliver care in residences for OSC. This study's objective was to identify the desirable characteristics of caregivers through qualitative interviews with directors of residences for OSC across four countries: Cambodia, Ethiopia, India and Kenya. A total of 28 interviews were conducted in the directors' local languages. Interviews were transcribed, translated into English, and analyzed using NVivo software. A thematic analysis of the data yielded three domains: personal qualities, skills, and religion. Across all the study geographic regions, most participants looked for similar characteristics in caregivers, such as love, patience, teamwork and communication skills, especially communicating about difficult child behaviors. These findings can inform plans to enhance effective and sustainable caregiving at residential care sites for OSC and simultaneously benefit the well-being of caregivers. Residential care directors may consider organizing workshops on teamwork and communication skills that will help improve the quality of caregiving.
\end{abstract}

Keywords Orphaned and separated children $\cdot$ Caregivers $\cdot$ Residential care centers $\cdot$ Lowand-middle income countries · Coping

Electronic supplementary material The online version of this article (https://doi.org/10.1007/s41042-02000041-9) contains supplementary material, which is available to authorized users.

Blen M. Biru

biru22b@mtholyoke.edu

Extended author information available on the last page of the article 


\section{Introduction}

It is estimated that there are close to 140 million orphaned and separated children (OSC) across the world (UNICEF 2017). Based on the UNICEF report, Asia and Africa have the highest number of OSC, with 61 million and 52 million OSC, respectively. Countries around the world have children who are orphaned and separated, either because one or both of their parents have died, or because the parents have too few resources to care for their children. Research shows that the majority of these children are raised by their surviving family members and not in residential care centers (UNICEF 2017). However, the number of children living in residential care centers such as group homes is not negligible, at more than two million (Whetten et al. 2014). These children are cared for by caregivers. The term "residential care centers" includes orphanages but is also broader in that it includes places for children to live for periods of time, if their parents are still alive but unable to care for them full-time. We, therefore, use the term "residential care centers" rather than "orphanages" in this paper.

It is important to note that such care centers can have different structures. They range from small to large facilities and either have caregivers working in shifts or have residential caregivers (Whetten et al. 2014). Residential caregivers mostly live at the residential care center and serve as a consistent parent figures, leading a household which comprises a certain number of children. For example, two of our study care centers in Ethiopia have multiple houses in which one caregiver, called "mother" by the children, cares for eight or nine children until they are grown. In a different model, caregivers who work in shifts usually are on duty a few days per week, and on the other days lead lives independent of the children they care for in the residential care centers (Whetten et al. 2014).

Caring for, raising, and educating children is important work that is essential to the well-being of orphaned and separated children, who will go on to become adults who might contribute to society in numerous beneficial ways, or possibly burdensome ways. Research supports the idea that caregivers play a critical role in children's lives. Thielman et al. (2012) point out that caregivers' poor health could be associated with the poor health of the children for whom they care. A study in Swaziland found that the economic and social empowerment of female caregivers not only increased caregivers' earnings but also resulted in increased protection and well-being of children (Makufa et al. 2017). In the Swaziland study, economic empowerment revolved around financial security, wherein caregivers were introduced to savings, loans, and establishing small businesses. These groups of women were also provided a discussion platform to learn about prevention of HIV and gender-based violence, as well as the care and support of children. The results showed that integrated economic and social support had positive outcomes in improving the lives of caregivers and children. Whetten et al. (2014) echo the importance of caregivers in residential care centers. Their longitudinal data, collected both from children who live in residential care centers and those who live with family members, enabled comparison of child outcomes between settings. They found that the caregiving structure in residential care centers was just as functional as in family-based settings. To the children, caregivers were like parents in the residential care centers they live in. They also found that child well-being outcomes were related to the quality of caregiving, and not to residential versus family-based settings per se, underscoring the important role caregivers play in shaping the lives of children in residential care centers. 
Notwithstanding the crucial role of caregiving, research has shown that the demands can be overwhelming and stressful. A large part of the available literature addresses the burdens of caregiving, such as burnout and fatigue (Branch and Klinkenberg 2015). In addition, studies have found that caregivers experience increased levels of stress and depressive symptoms while caring for others (Branch and Klinkenberg 2015; Brown et al. 2018; Gouin et al. 2012; Kidman and Thurman 2014). The increased levels of daily stressors can put caregivers at risk for chronic diseases such as heart disease (Chandola et al. 2006).

Despite literature on the demanding and stressful nature of caregiving, there is little information from a strengths-based perspective, such as the characteristics that caregivers need to deliver effective care. The few studies that highlight desirable caregiver characteristics focus on caregivers who take care of their own family members (Kidman, \& Thurman; Biru et al. 2015). One study conducted in Ethiopia showed that committed family caregivers of orphans relied on their belief in God and support from health workers to get through the challenges they faced (Biru et al. 2015). While addressing the burden of caregiving is important, previous literature has left a gap when it comes to discussing the characteristics of residential caregivers that help them support children. This study aims to address this gap and highlight strengths-based characteristics of residential (non-family) caregivers of OSC.

Studies in other contexts have explored the dispositions and attitudes needed to be effective at an occupation. For example, Goldie et al. (2015) suggest that identifying what makes a good clinical student and teacher could help with the training and assessment of students and teachers. The researchers distinguished the principal characteristic of good clinical students as being proactive and the principal characteristic of good teachers as relationship building skills. The authors also found that enthusiasm is a characteristic that is displayed by both good clinical students and teachers. Similarly, it would be beneficial to highlight the desirable characteristics of OSC caregivers for stakeholders interested in caregiving, to better understand the qualities, broadly construed as personality characteristics, skills, and coping strategies, that directors look for in OSC caregivers. Identifying these characteristics, skills, and coping strategies may help residential care directors promote both child and caregiver well-being.

Positive psychology researchers have considered individuals' strengths through multiple lenses, sometimes drawing on the work of philosophers. For example, Aristotle considered the pursuit of virtue and excellence to lead to positive by-products; most relevant here, the pursuit of virtues such as kindness may lead to both excellent caregiving of children and personal meaning found in relationships with children (Aristotle, fourth Century B.C.E./ 1985). A prominent treatment of virtue in psychology is the Values in Action (VIA) classification of Strength (Peterson and Seligman 2004). The VIA is composed of six virtues (i.e. courage, temperance, justice, humanity, transcendence, and wisdom) defined as "the core characteristics valued by moral philosophers and religious thinkers," and divided into 24 character strengths (e.g. creativity, love, forgiveness, and gratitude) defined as "the psychological ingredients - processes or mechanisms - that define the virtues" (Peterson and Seligman 2004, p.13). These virtues and character strengths may be useful in pointing to qualities desirable in caregivers of children. However, there has not been much research applying these conceptualizations to real world situations, and it is not known how diverse directors of residential care centers think about the strengths of OSC caregivers. Researchers have called for more studies in which respondents from diverse cultural contexts propose character strengths, rather than solely reacting to a list generated by 
Western thought such as reflected in the VIA (Kinghorn et al. 2019). Qualitative interviews could be one means of surfacing caregiver-specific character strengths as perceived by residential care center directors in different settings.

To that end, this study's objective was to identify desirable, strength-based characteristics of caregivers working in residential care centers for OSC through qualitative interviews with residential care directors in four countries: Cambodia, Ethiopia, India, and Kenya. By hearing from directors across four countries with different cultures, values, and religions, we hoped to enhance positive psychology frameworks by identifying strength-based caregiver qualities that would be widely applicable. In addition, because Cambodia, Ethiopia, India, and Kenya have large numbers of children living in residential care centers, we hoped our findings would benefit residential care center directors and future caregivers in those specific settings.

\section{Methods}

\subsection{Recruitment}

This study was conducted by a large team of investigators at Duke University and four local non-governmental organizations (NGOs) in the four study countries. These NGOs advocate for child well-being and were recruited from an ongoing study led by one of this study's authors. The established relationship served as a foundation to conduct the current study in partnership with the four NGOs:

India - Sahara Centre for Residential Care and Rehabilitation.

ACE Africa - Kenya (Action in the Community Environment-Kenya).

Ethiopia - Stand for Vulnerable Organization (SVO).

Cambodia - Homeland Foundation.

The NGO directors and staff were well-informed about orphans, the local culture, and research methods. In each site, NGO staff recruited directors of orphaned and separated children (OSC) residential care centers. Prior to data collection, the overarching study investigator (second author) met with the NGO directors and interviewer staff and conducted a training on the intent behind each interview question. The interviewer staff then contacted the directors of the residential care centers to explain the study. Residential care center directors had to meet the following inclusion criteria: age 18 years old or older and director of a residential care center for OSC, with at least one caregiver whom they supervise. In addition, we sought to interview directors from diverse OSC care centers in each geopgrahic region. When possible, we sought to interview directors of residential care centers that had different religious affiliations, i.e. secular vs religious, and that had caregivers of different religions (e.g., Hindu, Muslim and Christian caregivers in India). In addition to differences in religion, residential care centers were different in structure (private and governmental). The number of director interviews was largely determined by how many OSC residential care centers existed in each geographic region and willingness to participate in the study.

\subsection{Data Collection}

Residential care center directors who were interested and gave written consent were interviewed. All of the interviews were conducted by NGO interview staff, except for 
two interviews in Ethiopia conducted by this paper's lead author (a native speaker of Amharic). The in-depth qualitative interview guide asked about the characteristics, including the personal qualities and attitudes of effective caregivers in a demanding environment from the director's perspective. The interview guide also asked about how caregivers' religion may or may not affect caregiving; this was included based on the study's funder's interest in the role of religion and on published articles highlighting the role of religion in caregiving (Biru et al. 2015). Questions included:

- What are the personal characteristics and personality traits you think are important for caregivers to care well for others across time?

- What, in your opinion, are some of the most important things that caregivers do?

- Does religion have any part in good caregiving?

All of the interviews were audiotaped and conducted in the participant's language. Interviews took an average of 1 hour. Interviewers transcribed the interview in its original language and then translated it into English.

\subsection{Data Analysis}

Thematic analysis was conducted primarily by the first author, who first read through each interview, in collaboration with the second author. On one transcript per geographic region, she next conducted "open coding," whereby she identified units of meaning and assigned them a representative word or phrase (i.e., code). This resulted in a list of datadriven codes, described in a codebook with the definition and name of the code. On the remaining transcripts, she then conducted "focused coding," classifying the data using the coding schemes in the codebook. When data did not fit within the codes, she created additional codes. Also, during analysis, she wrote two types of memos for each transcript. The first was a summary memo that highlighted themes in the data that were especially important per transcript and geographic region. The first round of memo-ing revealed convergent themes within countries, therefore, the second set of memos created were interpretive memos with emerging insights aggregated across countries. Although, we looked, there were not codes and themes that arose frequently and prominently within a subset of geographic regions. Memos were also used for cultural context to help with the interpretation of the results.

We used the software NVivo version 11.0 (QRS International 2017) for coding and data organization. A second member of the research team coded $10 \%$ of the interviews, and the two team members met to reconcile any discrepancies in coding (Miles et al. 2014). The first author then reviewed the data for each specific code, identifying overarching themes that captured the coded text. The themes emerged from the interview data as well as the data analysis process. In addition, to capture ideas that cut across codes, the first author validated the findings by reviewing the data in an effort to refute the idea or, if not refuted, find additional support for it (Miles et al. 2014). Finally, similar themes that emerged were assembled to make up larger domains. In addition to the analysis and inter-coder reliability check of the first author (who is originally from one of the geographic regions), the entire coding and interpretation process was also guided by the second author. To avoid idiosyncratic interpretations, additional input was provided by the multi-disciplinary research team comprised of a member that conducted 
OSC research in the four geographic regions (Ethiopia, Kenya, India, and Cambodia) for more than 10 years and other qualitative research and cross-cultural experts. Furthermore, themes that emerged in each geographic region were shared in writing and discussed on virtual platforms with data collectors and site principal investigators based in each of the four geographic regions to ensure accuracy in analysis and interpretation. Questions such as "Do any of these findings resonate with you or surprise you? If so, why?" and "Which of the findings are the most relevant to caregiving in your setting?" were used to facilitate the discussion. During these meetings, international collaborators provided feedback that the research team incorporated.

\subsection{Ethics Approvals}

All procedures were approved by the Duke University Arts \& Sciences Institutional Review Board (IRB). We also secured local IRB approvals at each site:

- Local approval through Sahara Centre for Residential Care and Rehabilitation in India

- Local approval through Stand for Vulnerable Organization in Ethiopia

- Country-level approval by Kenya Medical Research Institute

- Country-level approval by National Ethics Committee for Health Research in Cambodia

The research was conducted in accordance with the ethical standards as laid down in the 1964 Declaration of Helsinki and its later amendments. Compensation for directors differed by geographic region and per their local IRB protocols. Some residential care centers did not compensate directors, whereas others gave a small gift to the director or to the residential care center as a whole. Informed consent was obtained from all individual participants included in the study.

\section{Results}

A total of 28 participants across four countries consented and were interviewed (see Table 1). The participants managed residential care centers with caregivers of different religions (Christianity, Islam, Hinduism, and Buddhism), and some of the centers themselves were affiliated with different religions $(n=16)$ (e.g. Catholic, Buddhism) and less than half were secular $(n=12)$ (see Table 2). Only two of the religiously affiliated residential care centers indicated their preference of hiring caregivers who follow the center's religion. Only one person was interviewed per residential care center, such that the data reflects the experiences of directors from 28 different residential care centers.

Participants named many qualities that they desired in caregivers, and separate codes were developed for each of the qualities. We found that desirable characteristics of caregivers working in residential care centers for OSC could be organized into three domains: personal qualities, skills, and religion. The themes that were aggregated to form the domains are discussed under each domain below. The themes under personal qualities and skills were mentioned spontaneously by participants in response to 
Table 1 Number of Participants by Geographic Region

\begin{tabular}{lll}
\hline Country & City & Number of participants \\
\hline Ethiopia & Addis Ababa & 6 \\
Kenya & Bungoma & 7 \\
Cambodia & Battambang & 4 \\
India & Hyderabad & 6 \\
& Nagaland & 5 \\
Total & & $\mathbf{2 8}$ \\
\hline
\end{tabular}

general questions related to good caregiving such as: "What do successful caregivers do when challenges come up?," and "What are the personality traits you think are important for caregivers?". On the other hand, the responses related to the role of religion in good caregiving were prompted by a specific question: "Does religion play a role in good caregiving?"

\subsection{Personal Qualities}

\subsubsection{A Good Caregiver Is a Loving Person}

The most important personal quality that was endorsed by almost all participants was love. Two participants from Cambodia and at least three participants from each of the other geographic regions mentioned the importance of love in the work that caregivers do. They discussed how love is what the children in these care centers are most deprived of, having lost their parents or not having their parents around for other reasons. Hence, the residential care centers are responsible for filling that gap in the children's lives:

"The important thing in caring for children is the feeling from deep inside (not pretense) that she is my sister, he is my brother. Unless they feel inside, if that feeling/concern is not there, they cannot look after the children. That is why the most important thing "love for children" has to be developed. Especially the care

Table 2 Religious Affiliation of Sampled Residential Care Centers

\begin{tabular}{lllllll}
\hline \multirow{2}{*}{ Geographic Region } & \multicolumn{2}{l}{ Religious Affiliation } & & \\
\cline { 2 - 7 } & Christian & Muslim & Hindu & Buddhist & Non-religious / Secular & Total \\
\hline Kenya & 5 & 1 & 0 & 0 & 1 & 7 \\
Nagaland & 2 & 0 & 0 & 0 & 3 & 5 \\
Hyderabad & 1 & 1 & 3 & 0 & 1 & 6 \\
Ethiopia & 1 & 0 & 0 & 0 & 5 & 6 \\
Cambodia & 1 & 0 & 0 & 1 & 2 & 28 \\
& 10 & 2 & 3 & 1 & 12 & 4 \\
\hline
\end{tabular}


center is like an orphanage home, like a children's home... because all the children need love." (Nagaland director).

Even though love was named as the most important caregiver characteristic unanimously, it is interesting to note the varied ways that participants defined love. Some participants viewed love as caregivers spending time with children and not just fulfilling their material needs. In Ethiopia, one participant presented love as an affection that is displayed in the things caregivers do, be it feeding children or giving them a hug. In Cambodia, a participant mentioned ways of showing love as quality time, giving gifts, treating children fairly regardless of their identity, and bodily connection. In Hyderabad, love seemed to be paramount in the eyes of the participants, with six out of seven participants underlining its importance. For one participant in Hyderabad, love appeared to be more important than education level: "We only look at love and affection; we don't look at their degree." Love was also symbolized as a motherly behavior or viewed as a means of earning motherhood.

\subsubsection{Service Mindedness or Commitment Contribute to Good Caregiving}

The second most important characteristic identified was commitment or being service minded, which is very much related to love. Service mindedness and commitment highlighted the importance of being devoted to one's work for the love of the job and not for alternate motivations. More than half of the participants (15 out of 27) indicated that commitment is important for good caregiving. The participants in Nagaland, Ethiopia, and Cambodia used the term 'commitment,' and participants from Hyderabad and Kenya used the term 'service minded.' In addition to loving the job and spending time with children, five participants discussed commitment in relation to money. Given that most of the residential care centers where we interviewed directors were not financially stable, participants preferred caregivers who were willing to serve the children even if there was no salary, for the love of the children.

\subsubsection{Patience Is Essential to Become a Good Caregiver}

At least two participants at each site reported patience as an important personal quality to be a good caregiver. Participants described the nature of caregivers' work to explain why they consider patience to be important. Patience was mainly important for dealing with children's misbehavior. The participants reported that children in residential care exhibit difficult behaviors, especially during puberty; hence, participants indicated preferring having caregivers who can handle such situations patiently. The participants stated that caregivers are expected to be patient as they work through problems that arise with children, and also simply to understand children well. A participant in Hyderabad explained:

"As I told you, [the caregiver] has to be patient, because to work in an OSC care center, a lot of patience is very much required. [For example,] not losing patience and getting frustrated if ten children come and started shouting all at once. [The caregiver] has to listen to every issue the children bring in and understand every child." 


\subsection{Skills}

\subsubsection{Communication Is an Important Skill that Caregivers Should Possess}

More than half of the participants (two participants from Kenya and at least three participants from each of the other geographic regions) underlined the importance of communication. Participants discussed communication mostly in light of the challenges caregivers face in residential care centers. They reported that the number one challenge caregivers face in all the residential care centers is dealing with children's difficult behaviors. To deal with behavioral challenges in residential care centers, participants valued caregivers who communicate with the children by openly discussing the behavioral problems with them and solving the issues. Participants emphasized the importance of communicating with center staff and managers equally:

"We come together and we discuss, have a dialogue and discuss, and see what best way we can solve any problem. There will be problems always, so we can solve the problem only by dialogue, asking together, coming together, discussing in the meeting and like that." (Nagaland director).

In addition to dealing with difficult behaviors, the importance of communication was highlighted when children get sick. Directors expressed that caregivers need to quickly act in certain situations and report to the appropriate party as soon as possible.

\subsubsection{Teaching Is an Important Skill that Caregivers Should Possess}

For 10 out of the 27 participants, they reported that teaching was part of the important work that caregivers do. They indicated that in most residential care centers, caregivers have responsibilities other than taking care of the children, and teaching is one of the things they are also expected to do. Teaching was discussed differently in geographic regions, ranging from household chores, activities like gardening, and ethical teachings (e.g., discipline and good manners), as well as religious teachings based on the residential care center. The participants hired caregivers not only to complete the daily tasks of caregiving, but also to serve as role models to the children. In the participants' opinions, caregivers shaped the children's future by instilling good manners and skills in them at a young age. Even though teaching was discussed to a certain degree in all geographic regions, it was a little more emphasized in Cambodia, with the majority of the participants (three out of four) endorsing its importance. In the following quote, a participant notes the teaching of both household chores and ethical teachings:

"We divide education into two ways: general knowledge and, as a mother, she has to educate the children about livelihood, good manners, and virtue in order to make the children be able to live together. Even though they are not their relatives, they live under one roof, so they must know how to do housework. Some children know nothing about this." (Cambodian director). 


\subsubsection{Teamwork Is an Important Skill that Caregivers Should Possess}

Participants across all geographic regions presented the nature of the work as collaborative. To that end, more than half of participants in Kenya (four out of seven) valued caregivers who were good at teamwork. At least one participant in each of the other geographic regions also discussed the importance of teamwork. The most common example of teamwork was caregivers covering for each other when someone became sick. Participants also highlighted that there should be no division of labor, indicating that every caregiver should feel responsible for completing tasks in the residential care center regardless of their specific assigned tasks.

"Mostly, first of all is to agree on teamwork. You know I have not come to do my own (personal) thing here, so I must develop teamwork. Behaviors of teamwork are very good for supporting the work of the OSC residential care centers to continue." (Kenyan director).

Teamwork was described as a way to foster the family-like structure that all participants wish to build in their care centers. Participants indicated that this togetherness, covering for each other, and operating like a family unit was not limited to caregivers but applied to the rest of the staff, as well. It is important to note that caregivers had interactions with other staff and their supervisors in addition to their interactions with children. One director in Hyderabad described the togetherness spirit among caregivers and the director as a family. "[The relationship between caregivers] has become like family. None of us care for our salary or say 'this is your job' 'this is my job'; it's not like that, it's all become like a family. Every work that we do, we do together. We have family devotion time where we discuss the needs and the improvement of the children. Sometimes, we have dinner together, sometimes we have lunch together."

A director in Nagaland noted similar sentiments of togetherness: "We must appreciate a good relationship among the children and caregivers. We dance together, we sing together, we have fun together, sometimes we organize a campfire outside and play around which brings us closer."

Similarly, in Ethiopia, caregivers' functions and collaborations extended from professional meetings to non-work related gatherings: "[Caregivers] have a two-hour weekly meeting. During this meeting, they can choose to meet with me [the director] or also just meet by themselves. They have representatives who take meeting minutes and share suggestions with the management team. In addition to these meetings, they have casual meetings once a month where they relax and spend quality time. They share positive experiences and challenges. They go out of town once in three months; this is supposed to help with burnout and clear their minds off work."

\subsection{Religion}

The third domain that arose from participants' interviews was the importance of religion to good caregiving. The majority of participants (19 out of 27 , with at least four from each site except Cambodia, explained below) indicated that religion plays a big role in good caregiving. There were three different perspectives that emerged in the way participants described the role of religion. 


\subsubsection{Religion Encourages Caregivers to Follow its Principles}

Directors from Nagaland and Kenya presented the idea of caregivers following their religious teachings in Christianity and Islam. Specifically, participants mentioned following Jesus, because Jesus loves children and practicing Islam, because Islam preaches about helping one another. One participant said, "We, from the Christian background, we know how Jesus loves children, and we follow that footstep." (Nagaland director).

In Cambodia, Buddhism is the predominant religion. Participants indicated that caregivers follow the five virtues of Buddha: do not kill, do not steal or rob, do not tell a lie, do not drink alcohol, and do not rape. They also indicated that these virtues provided guidance on caring for children.

\subsubsection{Religion Can Refrain Caregivers from Doing Bad Deeds}

This theme emerged clearly among directors of Christian residential care centers in Ethiopia. Three out of six Ethiopian participants mentioned the idea that it's possible to do wrong acts, because no one is around to watch. However, they referred to knowledge of the existence and omnipresence of God as 'fear of God,' making people more cautious in their work, because they know that God is watching all the time:

"Yes, this is true, in my opinion that religion has an impact on good caregiver activities. Because if the caregiver has religion, she may keep herself from doing bad things to children, because she [is] afraid of God." (Ethiopian director).

This theme also emerged in Nagaland and Kenya, where two participants reiterated fear of God.

For participants in Cambodia, refraining from bad deeds was governed by Buddha's principles: "Religion teaches us not to tell a lie or to steal someone's property. It is sinful if we do that. And the five codes of conducts of Buddha [refrain from taking life, from taking what is not given, from the misuse of the senses, from wrong speech, from intoxicants] are the best."

\subsubsection{Religion Promotes Good Deeds in Caregiving}

This theme highlighted the impact that religion has on the work that caregivers do. Participants discussed religion as a way of promoting good deeds. A participant from Kenya said: "It teaches kindness, forgiveness, love, helping each other, and being each other's keepers. Religion helps caregivers have a conscience when caring for the OSCs." Another participant from a Muslim residential care center in Kenya said that caregivers would be more cooperative and avoid disputes because they are bound by religion. One participant in Hyderabad talked about the aspect that their religion (Christianity) preaches about helping one another, which motivates caregivers to do good.

In Cambodia, a common Buddhist thought that people remind themselves of during challenging moments is "do good, receive good; do bad, receive bad," which encourages them to enact good actions rather than bad, both to instill immediate peace in their 
hearts and to offer good karma. "Our Buddhism always preaches about the role of parents/ caregivers, how to have a peaceful mind." Participants also reported that caregivers draw from their religion other qualities such as kindness, forgiveness, and morality to promote good caregiving: "For Buddhism, we use kindness and forgiveness; they play a very big role in our caregiving."

From the above three themes described, it is clear that religion is important to most participants, regardless of the residential care center's background (whether it was faithbased, private or government run). Given its importance, two participants showed concern associated with having caregivers of different religions, while most did not. One participant from Kenya and one from Hyderabad who each valued religion and came from a faith-based organization clearly stated that they would prefer hiring a caregiver who followed their own religion. A participant from Kenya said: "Because we are a Christian-oriented care center, we only hire caregivers of a religious background who are mostly Christians, because they can be trusted around children and can teach children good virtues and morals. Otherwise, we might get someone who will lead kids astray and instill bad or negative virtues." Other participants who valued religion did not necessarily look for a certain religion while hiring caregivers.

These strong religious opinions can be explained by the directors' view of the role of religion in the residential care center. Some participants in Cambodia and Nagaland stated that they would like caregivers to teach their religion to children: "Since we are Christians, we teach them [the] Bible. In the Bible, there are many life principles we benefit from. When we teach those principles to the children, they apply it in their lives and improve their lives." In such cases, teaching religion appears to be part of a caregiver's duties, which might be why some directors of OSC choose to hire from a particular religion. On the other hand, some participants mentioned that their residential care center was secular, and thus they did not recruit based on religion. Even if they personally valued religion, it was not a standard they could include as a criterion when recruiting caregivers. Whether participants used religion as a basis for hiring or not, it was clear that it played a role in the lives of caregivers and children.

\section{Discussion}

This study contributes to the literature by identifying the perspectives of directors of residential care centers on the positive qualities of caregivers, with participants from four countries and multiple residential care settings. It addresses a gap in identifying desirable and positive personality characteristics, skills, and coping strategies possessed by caregivers perceived as effective. Given the approximately two million children in residential care centers across the world, it is critically important to learn about and support their caregivers, both for the benefit of the children and the caregivers themselves.

When residential care center directors were asked about desirable characteristics of caregivers, which centered on personal qualities, skills, and religion, responses were mostly alike across the four countries and five different geographic regions. Even though these regions were in different countries and cultures, it appeared that universal themes emerged, possibly due to the common feature of all being directors of residential care centers for OSC. First and foremost, what makes the perspective of the 
directors similar is the fact that the children they supported were separated and deprived of love from their biological parents. Hence, it is no surprise that love was found across geographic regions to be the most important personal quality a caregiver can possess.

Positive psychology researchers have studied character strengths and developed taxonomies of such strengths, most notably in the form of the VIA Character Strengths (Peterson \& Seligman., 2004). This set of 24 strengths organized under six virtues was developed through a series of meetings with European and North American scholars. Strengths were included based on being ubiquitous, contributing to individual fulfillment, and being valued in their own right and not as a means to an end (Peterson and Park 2009). The current study adds to the literature by identifying strengths that residential care directors from diverse cultural contexts name for caregivers of children, without being prompted to name the list of strengths developed by European and North American scholars.

Directors in the current study emphasized love, which is one of the VIA character strengths classified under the virtue humanity. The VIA defines love as "the degree to which you value close relationships with people, and contribute to that closeness in a warm and genuine way" (Peterson and Seligman 2004). The way directors described love is consistent with this definition. This study adds to our knowledge of how the character strength love is applied in residential care settings. Examples of love emphasized caregivers developing intimacy with children through treating them fairly, being friendly with them, communicating kindly, and giving them gifts and physical affection, such as hugs, to foster the closeness.

Residential care directors also named service mindedness or commitment, with the wording nuance depending on their geographic region. This character strength is not specifically included in the VIA, although it is consistent with the virtue, humanity. Nevertheless, the addition of a character strength not included in the VIA indicates the importance of allowing respondents to propose strengths and not just respond to a preset list. The directors also named patience, which has long been considered to be a virtue, and fits with the VIA virtue of temperance. One of the VIA's virtues is transcendence, with the corresponding character strength of spirituality, which relates to the features of religion described by the residential care directors.

In addition to these character strengths, the directors indicated that they desire caregivers who perform well in a team and enjoy teaching children, including modeling household chores and teaching morals. While teamwork and teaching are not character strengths per se, they are both indicators of good psychological functioning. Positive psychology researchers have highlighted psychological functioning as an element of eudemonia (Ryff 1989; Huta and Waterman 2014). Identifying teamwork and teaching, including moral teaching, is a caregiverspecific contribution to the literature.

Turning away from researcher frameworks and toward an applied perspective, characteristics like communication and patience were mostly referenced in response to caregiving aspects that children and residential care centers worldwide can experience. These characteristics were seen to be necessary in times of challenges. The challenges identified by participants included dealing with difficult behaviors of children, as well as interacting with children as they undergo puberty. Given the universality of puberty and behavior problems, it is natural for participants from different geographic regions to look for similar characteristics in caregivers. 
The finding that religion has a role in good caregiving is consistent with prior literature (Biru et al. 2015). The role of religion in these residential care centers may not be surprising given that they are located in countries with a low percentage of the population unaffiliated with religion; in India (Nagaland and Hyderabad), Ethiopia, and Kenya; the unaffiliated percentages are: $<0.1 \%,<0.1 \%$, and $2.5 \%$, respectively (Pew Research Center 2012). From these statistics, we can see how religion is not only a part of caregivers' lives but also the larger society's. To that end, participants' preference for religious caregivers could be related to having the children familiarized with religious principles so that it is easier for them to integrate into society. The fact that these countries are largely religious is also reflected in the sampled residential care centers, where more than half were affiliated with a certain religion (16 out of 28 residential care centers). The religious nature of the care centers make the directors' emphasis on religion not surprising. Directors leading those residential care centers may be drawn to caregivers who embody the principles of the religion the residential center follows.

The character strength of commitment has also arisen in other studies. A study in Ethiopia assessing the experience of family caregivers of children living with HIV found that caregivers were highly committed, even though they experienced extensive worry, caring burdens, and disrupted family and social networks (Biru et al. 2015). The commitment of the caregivers to their family members was primarily attributed to their belief in God, as well as receiving support and counseling from healthcare workers. This religious motivation relates to the results of the current study, as well. In this study, we learned that more than half of residential care center directors looked for commitment and someone with faith. It is possible that religious faith helps bolster one's commitment to children.

In this study, we focused on OSC caregivers, but there are many kinds of caregiving needs, and therefore caregivers, around the world. Studies on other kinds of caregivers have highlighted the importance of family support. For example, a study conducted on caregivers' resilience in a cancer care setting found that lack of family support may lead to lower resilience (Hwang et al. 2018). Another study involving caring for aging parents in Japan indicated that social support is important for family caregivers (Kikuzawa 2016). Similar to these findings on the importance of social support, in our study, we found the importance of teamwork. Most participants described the interaction with caregivers as being like that of a family unit. Hence, the support caregivers provide each other, such as helping each other in times of sickness by covering shifts, could essentially be like family support.

Further, this study fits into other bodies of research that focus on caregiving for children with attention deficit hyperactivity disorder (ADHD). The researchers that looked into the needs of family caregivers with ADHD identified major communication problems between caregivers and the children they were caring for (Pahlavanzadeh et al. 2018). Parents who participated in the study stated that being able to communicate well with the children could possibly lead to positive outcomes for their children. Knowing how to punish and reward children is listed as an example of good communication. Our study findings support this result, as it underlines the importance of communication as caregivers daily interact with children at any capacity. Participants in our study discussed the need for understanding a child individually and knowing how to respond to a situation in a timely manner. It is likely that the findings from the ADHD study could be applicable to OSC caregivers, regardless of whether they interact with children with ADHD. 
Research on another type of caregivers, specifically caregivers of people living with dementia, has also reported on characteristics. The most relevant study we found reported an association between personal strengths and enhanced psychosocial functioning. The strengths identified included resilience, optimism, and a sense of coherence (Elnasseh et al. 2016). Resilience was defined as effective coping in times of adversity, optimism as being positive, and sense of coherence as being efficient by using positive coping methods. These strengths of resilience, optimism, and a sense of coherence are different from the current study's personal qualities of love, commitment, and patience. These differences in character strengths indicate that our study findings cannot be applied to all caregiver populations, as each type of caregiving can have its own demands for effective caregiving. That said, there are some shared characteristics such as commitment that proved to be important in different types of caregiving. More research needs to be done to understand the particular characteristics needed for different types of caregivers.

\subsection{Strengths and Limitations}

This study is unique given that our data were collected in four different countries, allowing for diverse director perspectives on desirable characteristics of caregivers. By virtue of collecting data in these four countries, we were also able to have diversity in participants' religion (Christianity, Islam, Hinduism, and Buddhism). We conducted the interviews in the participants' local languages, which increased the validity of our data. Nevertheless, this study has ist limitations. One limitation with our method was the possibility that a concept may have been misinterpreted in the translation and transcription process. We also did not have equal number of participants in each of the four countries. Consequently, it is possible that there was richer data from one country and that less was revealed from other countries, which may have led us to falsely conclude that, for example, patience might be more valued in one country than another. For this reason, we refrained from making such generalizable conclusions, although we indicated when a particular theme was mentioned less often in a specific geographic region. In the future, researchers may wish to interview more directors per country.

Personal Qualities

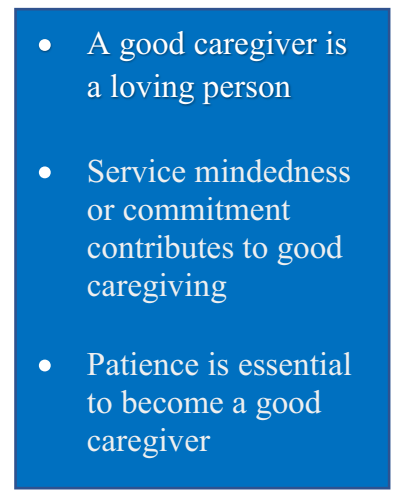

Skills

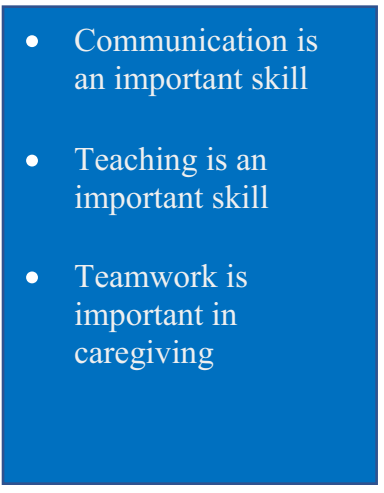

Religion

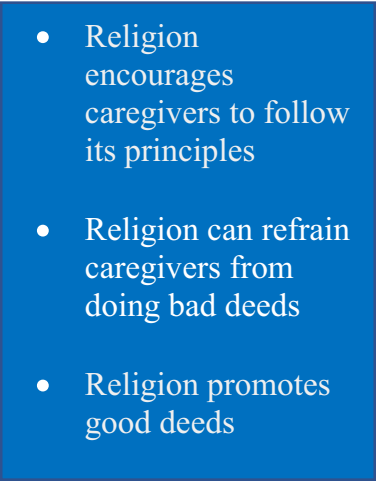

Fig. 1 Domains and Themes Residential Care Center Directors Identified for Good Caregivers 
Another limitation of this study could be that we asked about religion per our funder's emphasis and articles highlighting the role of religion in caregiving. It is possible that religion would not have spontaneously arisen without being asked about, however, participants discussed it in detail.

In addition, our study only identified desirable characteristics of caregivers based on the directors' perspectives, and not caregivers'. Further research on characteristics of effective caregiving can be done by including caregivers' perspectives.

\subsection{Recommendations and Implications}

From this study, we learned the desirable characteristics of caregivers, as perceived by residential care directors. Fig. 1 depicts the three major domains identified (personal qualities, skills, and religion), as well as the themes they entail and can be used as a practical guideline for directors of OSC caregivers themselves. The three most important skills (communication, teaching, and teamwork) which emerged from the data seemed to be more salient when it came to caregivers' relationships with staff and supervisors, as compared to the personal qualities (loving, commitment, and patience), which emerged from the data, which mostly revolved around caregivers' interactions with children. The third theme (religion) mostly dictated the actions of the caregivers. According to participants, the caregivers seemed to make decisions or rationalize their behavior based on their religious beliefs, for example, whether to help a child or not at a given moment.

Residential care center directors could use these findings to provide resources and training for communication skills, structures that allow religion to be practiced and supported by caregivers, and conditions where love can thrive (e.g., enough time and resources for caregivers to build strong relationships with the children they're serving). Furthermore, love could be sustaining for caregivers, providing authenticity, meaning, and purpose, in addition to promoting great care for children.

\section{Conclusion}

In this multi-site study, we identified different characteristics that residential care center directors desire in caregivers for orphans and separated children. A good caregiver was considered to be loving, service minded, and patient. S/he also was seen to possess skills such as communication, teaching, and teamwork, and, in many cases, to possess and be influenced by religious faith. It may not be possible for one caregiver to have all of these skills and qualities. However, it is important that directors pay attention to the characteristics that are the best fit for their residential care center and the children they serve. Directors may consider offering trainings and workshops in order for caregivers to develop the identified skills and, when possible, personal qualities. Directors may also consider offering time and venues for caregivers to participate in faith activities. Investing in the characteristics that make a caregiver effective may have a positive impact on the children's well-being, as well as on the residential care center's success. 
would like to thank: Augustine Wasonga and Mao Lang for their leadership at international child well-being NGOs; Chimdi Temesgen and Senti Tzudier for data collection, as well as for tailoring the data collection to their site's cultures and language; Dean Lewis, Tewodros Abera, and Lynn Akinyi for their financial oversight; Morgan Barlow and Andy Elkins for project coordination; Xiaoqian Liu for data coding and organization and most importantly, the study participants for their time and insight. Dr. Kaiser was supported by the National Institute of Mental Health of the National Institutes of Health under award number F32 MH113288.

Availability of Data and Material (Data Transparency) Upon request, we can discuss data access. Our data are hard to de-identify and had five separate IRB approvals.

Authors' Contributions All authors contributed to the research design or the acquisition, analysis, and interpretation of data. The first and second authors drafted the manuscript, other co-authors reviewed and edited the manuscript.

Funding Information This study was funded by a grant from Saint Louis University and the John Templeton Foundation as part of their Happiness \& Well-Being: Integrating Research Across the Disciplines Project.

\section{Compliance with Ethical Standards}

Conflict of Interest On behalf of all authors, the corresponding author states that there is no conflict of interest.

Ethical Approval All procedures performed in this study involving human participants were in accordance with the ethical standards of the institutional and/or national research committee and with the 1964 Helsinki declaration and its later amendments or comparable ethical standards.

Informed Consent Informed consent was obtained from all individual participants included in the study.

Code Availability (Software Application or Custom Code) Codebook is submitted.

\section{References}

Aristotle. (4th Century B.C.E./1985). Nicomachean ethics. (T. Irwin, Trans.). Indianapolis, IN: Hackett.

Biru, M., Lundqvist, P., Molla, M., Jerene, D., \& Hallström, I. (2015). Surviving overwhelming challenges: Family caregivers' lived experience of caring for a child diagnosed with HIV and enrolled in antiretroviral treatment in Ethiopia. Issues in Comprehensive Pediatric Nursing, 38, 282-299.

Branch, C., \& Klinkenberg, D. (2015). Compassion fatigue among pediatric healthcare providers. The American Journal of Maternal Child Nursing, 40(3), 160-166.

Brown, C. L., Lwi, S. J., Goodkind, M. S., Rankin, K. P., Merrilees, J., Miller, B. L., \& Levenson, R. W. (2018). Empathic accuracy deficits in patients with neurodegenerative disease: Association with caregiver depression. The American Journal of Geriatric Psychiatry, 26(4), 484-493. https://doi.org/10.1016/j. jagp.2017.10.012.

Chandola, T., Brunner, E., \& Marmot, M. (2006). Chronic stress at work and the metabolic syndrome: Prospective study. British Medical Journal (Clinical Research Ed.), 332(7540), 521-525.

Elnasseh, A. G., Trujillo, M. A., Peralta, S. V., Stolfi, M. E., Morelli, E., Perrin, P. B., \& Arango-Lasprilla, J. C. (2016). Family dynamics and personal strengths among dementia caregivers in Argentina. International Journal of Alzheimer's Disease. https://doi.org/10.1155/2016/2386728.

Goldie, J., Dowie, A., Goldie, A., Cotton, P., \& Morrison, J. (2015). What makes a good clinical student and teacher? An exploratory study. BMC Medical Education, 15(1). https://doi.org/10.1186/s12909-0150314-5. 
Gouin, J.-P., Glaser, R., Malarkey, W. B., Beversdorf, D., \& Kiecolt-Glaser, J. (2012). Chronic stress, daily stressors, and circulating inflammatory markers. Health Psychology : Official Journal of the Division of Health Psychology, American Psychological Association, 31(2), 264-268.

Huta, V., \& Waterman, A. S. (2014). Eudaimonia and its distinction from hedonia: Developing a classification and terminology for understanding conceptual and operational definitions. Journal of Happiness Studies, $15,1425-1456$.

Hwang, I. C., Kim, Y. S., Lee, Y. J., Choi, Y. S., Hwang, S. W., Kim, H. M., \& Koh, S.-J. (2018). Factors associated with caregivers' resilience in a terminal Cancer care setting. The American Journal of Hospice \& Palliative Care, 35(4), 677-683.

Kidman, R., \& Thurman, T. (2014). Caregiver burden among adults caring for orphaned children in rural South Africa. Vulnerable Children and Youth Studies, 9, 234-246.

Kikuzawa, S. (2016). Social support and the mental health of family caregivers: Sons and daughters caring for aging parents in Japan. International Journal of Japanese Sociology, 25(1), 131-149. https://doi. org/10.1111/ijjs.12041.

Kinghorn, W. A., Keyes, C. L. M., Parnell, H. E., Eagle, D. E., Biru, B. M., Amanya, C., Vann, V., Kaza, V. G. K., Tzudir, S., Saddo, Y. B., Whetten, K., \& Proeschold-Bell, R. J. (2019). Putting virtues in context: Engaging the VIA classification of character strengths in caregiving for orphans and vulnerable children across cultures. Journal of Positive Psychology, 14(6), 845-853.

Makufa, S. C., Kisyombe, D., Miller, N., \& Barkey, N. (2017). Empowering caregivers of orphans and vulnerable children in Swaziland. African Journal of AIDS Research, 16(4), 355-363.

Miles, M. B., Huberman, A. M., \& Saldaña, J. (2014). Qualitative data analysis: A methods sourcebook (3rd ed.). Thousand Oaks: Sage Publications, Inc..

Pahlavanzadeh, S., Mousavi, S., \& Maghsoudi, J. (2018). Exploring the needs of family caregivers of children with attention deficit hyperactivity disorder: A qualitative study. Iranian Journal of Nursing and Midwifery Research, 23(2), 149-154.

Peterson, C., \& Park, N. (2009). Classifying and measuring strengths of character. In S. J. Lopez \& C. R. Snyder (Eds.), Oxford handbook of positive psychology (2nd ed., pp. 25-33). New York: Oxford University Press.

Peterson, C., \& Seligman, M. E. P. (2004). Character strengths and virtues: A handbook and classification. New York: Oxford University Press.

Pew Research Center - The Global Religious Landscape 2012 - religious composition by country Retrieved January 4 2018, from: https://assets.pewresearch.org/wp-content/uploads/sites/11/2012/12 /globalReligion-tables.pdf

QSR International Pty Ltd. (2017). NVivo qualitative data analysis software; Version 11.

Ryff, C. D. (1989). Happiness is everything, or is it? Explorations on the meaning of psychological wellbeing. Journal of Personality and Social Psychology, 57, 1069-1081.

Thielman, N., Ostermann, J., Whetten, K., Whetten, R., O’Donnell, K., \& Team, the P. O. for O. (POFO) R. (2012). Correlates of poor health among orphans and abandoned children in less wealthy countries: The importance of caregiver health. PLoS One, 7(6), e38109.

UNICEF. (2017). Orphans. Retrieved January 4 2018, from: https://www.unicef.org/media/media_45279.html Whetten, K., Ostermann, J., Pence, B. W., Whetten, R. A., Messer, L. C., Ariely, S., \& Thielman, N. M. (2014). Three-year change in the wellbeing of orphaned and separated children in institutional and familybased care settings in five low- and middle-income countries. PLoS One, 9(8), e104872.

Publisher's Note Springer Nature remains neutral with regard to jurisdictional claims in published maps and institutional affiliations. 


\section{Affiliations}

Blen M. Biru ${ }^{1} \cdot$ Rae Jean Proeschold-Bell ${ }^{1,2}$ - Bonnie N. Kaiser ${ }^{3,4} \cdot$ Heather E. Parnell 1,2 . Venkata Gopala Krishna Kaza ${ }^{5}$. Ira Madan ${ }^{5}$ - Misganaw Eticha Dubie $^{6} \cdot$ Vanroth Vann $^{7} \cdot$ Cyrilla Amanya ${ }^{8} \cdot$ Kathryn Whetten ${ }^{1,2,9}$

Rae Jean Proeschold-Bell

rae.jean@duke.edu

Bonnie N. Kaiser

bkaiser@ucsd.edu

Heather E. Parnell

heather.parnell@duke.edu

Venkata Gopala Krishna Kaza

Vijaya_gk@rediffmail.com

Ira Madan

iramadan@gmail.com

Misganaw Eticha Dubie

misganaweticha.svo@gmail.com

Vanroth Vann

vanrothkhmer@gmail.com

Cyrilla Amanya

cyrillaamanya@gmail.com

Kathryn Whetten

k.whetten@duke.edu

Duke Global Health Institute, 310 Trent Dr, Durham, NC 27710, USA

2 Center for Health Policy and Inequalities Research, Duke University, 310 Trent Drive, CB 90392, Durham, NC 27710, USA

3 Department of Anthropology, Global Health Program, University of California San Diego, 9500 Gilman Drive \#0532, La Jolla, CA 92093, USA

4 Duke Global Health Institute, Duke University, Box 90519, Durham, NC 27710, USA

5 Sahara Centre for Residential Care \& Rehabilitation, H 62 D, Saket, New Delhi 110017, India

6 Stand for Vulnerable Organization (SVO), Addis Ababa, Ethiopia

7 Development for Cambodian Children, \#130, Group 09, Snapimuk Village, Prek Khpob Commune, Ek Phnom District, Battambang City, Battambang Province, Cambodia

8 Research Department, ACE Africa Kenya, P.O. Box 1185, Bungoma 50200, Kenya

9 Terry Sanford Institute of Public Policy, Duke University, Box 90239, Durham, NC, USA 